\title{
Standardization of techniques for raw mango candy production for rural entrepreneurship
}

\author{
A Singh, PS Gurjar, KS Yadav \& B Killadi
}

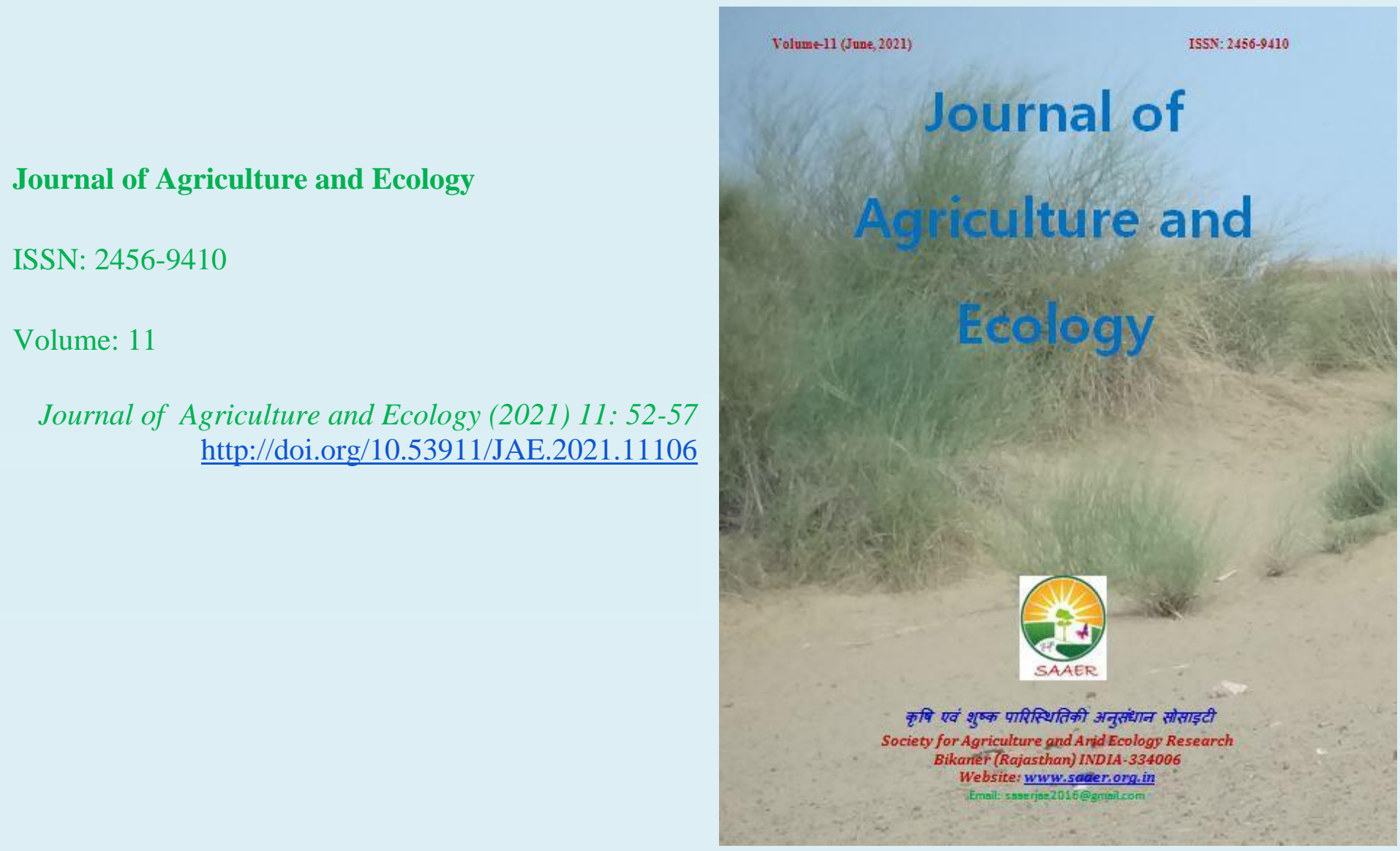




\title{
Standardization of techniques for raw mango candy production for rural entrepreneurship
}

\author{
A Singh ${ }^{1}$, PS Gurjar $^{2} \square$, KS Yadav ${ }^{3} \&$ B Killadi ${ }^{1}$ \\ ${ }^{I}$ Scientist, ICAR-Central Institute for Subtropical Horticulture, Lucknow \\ ${ }^{2}$ Scientist, ICAR-Central Institute for Arid Horticulture, Bikaner \\ ${ }^{3}$ Research Scholar, BBAU, Lucknow \\ Corresponding author: PS Gurjar, E-mail:pawan09996@gmail.com
}

\section{Article Info}

Article history

Received: 28 May 2021

Accepted: 25 June 2021

Available online: 30 June 2021

Key Words:

Standardization, mango, rural entrepreneurship.

\begin{abstract}
India is the largest producer and consumer of mango fruit and it is available for a longer period of time from February to September in different parts of the country. Mango is a rich source of antioxidants, Vitamin A, Vitamin C, Vitamin E, and fair amounts of iron and nicotinic acid. Raw mango fruits contained higher amount of polyphenols including flavonoids and thereby showing higher antioxidant properties. With the purpose of raw mango product diversification, raw mango candy of commercial varieties (Totapuri, Mallika and Dashehari) was developed during the mango season and evaluated for nutraceutical properties at three months and six months interval. Organoleptic evaluation of the product was assessed by using nine point hedonic scales. The total soluble solids, acidity, and reducing sugar increased, while ascorbic acid and antioxidant decreased during six months storage. Organoleptically Dashehari candy got highest score (8.5 out of 9) and Mallika lowest with score (7.8 out of 9). Highest TSS was recorded in Dashehari candy (73.50 B) and Lower in Mallika (66.50 B). Vitamin C was at par in Dashehari and Mallika i.e. $98.0 \mathrm{mg} / 100 \mathrm{gm}$ and lowest in Totapuri $70.0 \mathrm{mg} / 100 \mathrm{gm}$. Acidity was highest in Mallika $(0.81 \%)$ and lowest in Totapuri $(0.33 \%)$. No microbial growth was found in any sample during the storage period. This mango candy is a perfect diversification for utilization of raw mango as small scale enterprise for farm women. It will also give solution to mango dropping during wind storm during the month of AprilMay.
\end{abstract}

Copyright (02021 Singh et al., This is an open access article published under the terms of the Creative Commons Attribution License, which permits unrestricted use, distribution, and reproduction in any medium, provided the original work is properly cited.

Preferred citation: Singh A, Gurjar PS, Yadav KS \& Killadi B. 2021. Standardization of techniques for raw mango candy production for rural entrepreneurship. Journal of Agriculture and Ecology, 11: 52-57; http://doi.org/10.53911/JAE.2021.11106.

\section{Introduction}

Mango (Mangifera indica L.) is the most important fruit crop in tropical and subtropical regions of the world. Mango fruit is considered to be one of the best fruit in the world market because of its excellent flavor, delicious taste, beautiful colour, attractive fragrance and health giving properties (Salunke \& Desai 1984). Apart from its delicacy, it is a nutritionally important fruit being is an outstanding source of Vitamin-A and good source of Vitamin-C besides it has 
many minerals and other Vitamins. India produces 196.87 lakh tonnes of mango from 2.26 million hectares of area (NHB, 2016). Andhra Pradesh ranks first both in area and production and is followed by Uttar Pradesh. It is reported that about $75 \%$ of the fruits are knocked off, right from the flowering stage till ripening. The losses however, can be minimized to a great extent by utilizing the dropped fruits. Fortunately, mango is one of the fruit which can be utilized in all stages of maturity. The fruit is used as a dessert, as a table fruit between meals and is also processed for preparing a lot of products (Kumar et al. 2019; Anusuya et al. 2018). Established processed products include pulp, juice, squash, RTS, nectar, pickles, chutney, preserve, jam, canned slices, dried powder, pana and many other products. Raw mango fruits were not exploited so far for production of candy. Raw mango candy produced from matured raw fruits dropped due to strong storm often prevalent in May-June months may open new opportunities for entrepreneurship for rural women. Therefore, study was conducted to standardized techniques for raw mango candy production from commercial mango varieties.

\section{Material and Methods}

Mature raw fruits of commercial mango varieties namely; Dashehari, Amrapali and Mallika were procured from experimental farm of ICAR-Central Institute for Subtropical Horticulture, Rehmankhera, Lucknow. Raw mango candy was prepared by following steps given in flowchart 1.
Matured raw mango fruits

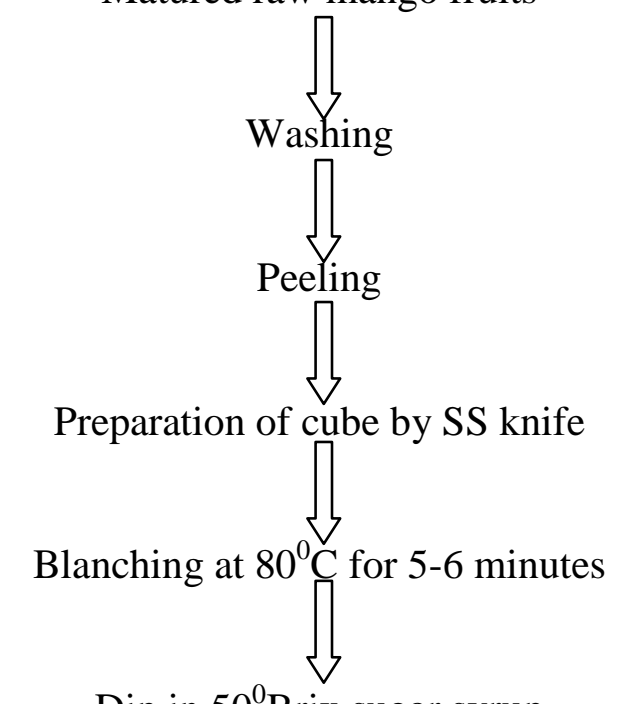

Dip in $50^{\circ}$ Brix sugar syrup

Draining of sugar alternate day till $65^{\circ} \mathrm{Brix}$

$$
\text { achieved }
$$<smiles>C=[Tl]</smiles>

Washing for removal of adhered sugar<smiles>[C]=C</smiles>

Drying in oven at $60^{\circ} \mathrm{C}$ for 8 hours

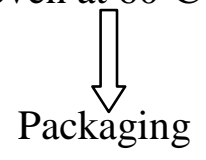

Flowchart 1: Preparation method of raw mango candy

\section{Biochemical analysis methods}

Determination of biochemical parameter is important in evaluating the quality of product/processed food product to assure its safety and quality for consumption. Biochemical analysis was conducted by using methods of Rangana (2010).

Moisture (\%) 
Ten gram of the sample was weighted in a washed and dried petri plate. Dry the sample in an oven at $100^{\circ} \mathrm{C}$, then cool in a desiccators and weight the Petri plate. Repeat the process of heating and cooling until the constant weight is obtained. Calculate by using the formula-

$$
\text { Moisture } \%=\frac{\text { Initial weight of sample }- \text { Final weight of sample } \times 100}{\text { Initial Weight of the sample }}
$$

\section{Total soluble solid (TSS)}

Total Soluble Solids was recorded by using hand refractometer. Small quantity of fruit pulp/candy is placed between the two prism of refractometer, reading is recorded and expressed in term of degree Brix $\left({ }^{0} \mathrm{~B}\right)$. The reading is corrected with the TSS- temperature correcting table. The zero error in the refractometer is adjusted with distilled water before recording TSS.

\section{Tritratable acidity (as \% citric acid)}

The acidity was estimated by titrating it against $0.1 \mathrm{~N}$ sodium hydroxide $(\mathrm{NaOH})$ solution using phenolphthalein as an indicator (AOAC, 1984). For acidity estimation $5 \mathrm{~g}$ of diluted pulp is weighted and volume is made up to $50 \mathrm{ml}$ with distilled water. $10 \mathrm{ml}$. of diluted pulp sample is taken in a conical flask and add few drops of phenolphthalein indicator. The solution is titrated against $0.1 \mathrm{~N}$ $\mathrm{NaOH}$ to definite light pink colour which persists for at least 30 seconds and records the titre value. $0.1 \mathrm{~N} \mathrm{NaOH}$ is standardized by titrating it against of $0.1 \mathrm{~N}$ oxalic acid. Calculate acidity as percent citric acid by the formula-

$$
\text { Acidity }(\%)=\frac{\text { Normality of alkali } \times \text { Eq. wt. of acid } * \times 100 \times \text { Titre value of sample }}{\text { Weight of sample } \times \text { aliquot taken for estimation X } 1000}
$$

filtrate is transferred into a separating funnel

\section{Total carotene content}

The total carotenoids are quantified by the spectrometric method. 2 g. of macerated pulp is weight and a pinch of magnesium carbonate is added. The carotenoids are extracted with $15 \mathrm{ml}$ of acetone by grinding with pestle and mortar. Extraction is repeated 3 times with acetone and finally with $15 \mathrm{ml}$ petroleum ether until the entire sample becomes colourless. The aliquot is filtered through cotton wool in to a conical flask. The Total carotenoid $=\frac{\text { Consn. of beta }- \text { carotene } \mathrm{x} \text { vol. made up x } 100 \mathrm{x} \text { OD value of the sample }}{\text { OD value of beta carotene } \mathrm{X} \text { weight of sample X } 1000}$

\section{Sensory evaluation}

All the panelists were briefed before evaluation. Sensory attributes like color, texture, taste and overall acceptability for all containing $10-15 \mathrm{ml}$ of $10 \%$ of sodium chloride solution. The mixture is then shaken and allow for separation in a stand. The carotenoids pigment layer is taken into a 25 $\mathrm{ml}$ volumetric flask. The volume is made up to $25 \mathrm{ml}$ with the solution of $3 \%$ acetone in petroleum ether. Keep the sample in dark for about 1-2 hours. The reading is taken in spectrophotometer at $452 \mathrm{~nm}$ using $3 \%$ acetone in petroleum ether as blank.

samples were assessed using nine point hedonic scales. Hedonic scale was in the following sequence: $9=$ Like extremely, $8=$ Like very much, $7=$ Like moderately, $6=$ 
Like slightly, $5=$ Neither like nor dislike, $4=$ Dislike slightly, $3=$ Dislike moderately, $2=$ Dislike very much and 1= Dislike extremely (Amrine, 1965). The samples were coded with letters and served to the panelists at random to guard against any bias.

\section{Statistical analysis}

The data obtained were subjected to statistical analysis by using 'Statistical Software Package for Agricultural Research Workers' (Sheron et al., 1998) software at $5 \%$ significance level.

\section{Results and Discussion}

The biochemical attributes are important parameters for commercialization of packed fruit by-products. The chemical constituents of mango candy such as TSS, titrable acidity (\%), moisture content and total carotene were estimated at zero days. Candies were also subjected to sensory evaluation.

\section{Total Soluble Solids}

Considerable variation was not noticed in TSS of candy prepared from commercial mango varieties viz; Dashehari, Amrapali and Mallika (Fig. 1). Almost equal TSS was observed in candies of Dashehari (80.75 ${ }^{\circ}$ Brix) and Amrapali (80.25 ${ }^{\circ}$ Brix) mango. However, candy prepared from Mallika had lower TSS than Dashehari and Amrapali candies. The justification for lower TSS of Mallika candy is higher TSS of fresh fruits of Dashehari and Amrapali.

\section{Titrable Acidity (\%)}

Maximum acidity (\%) was estimated in candy prepared from Mallika mango $(0.928 \%)$ while acidity of Dashehari $(0.688 \%)$ and Mallika $(0.688 \%)$ candies was found incidentally equal (Fig. 2). Higher acidity of candy from Mallika mango was attributed to more acidity in raw fruits used for preparation of candy.

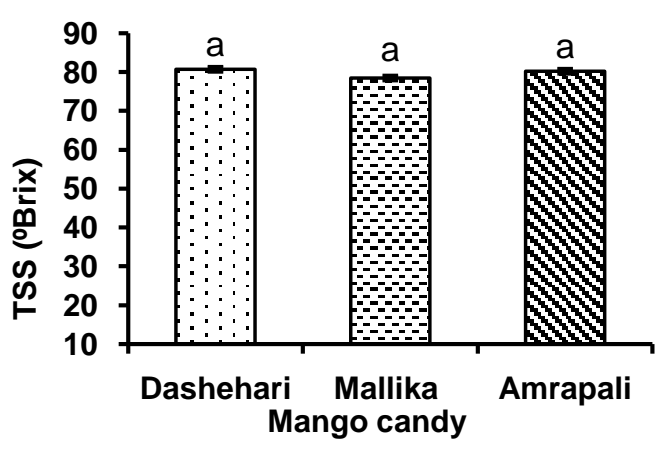

Figure 1. TSS of raw mango candy

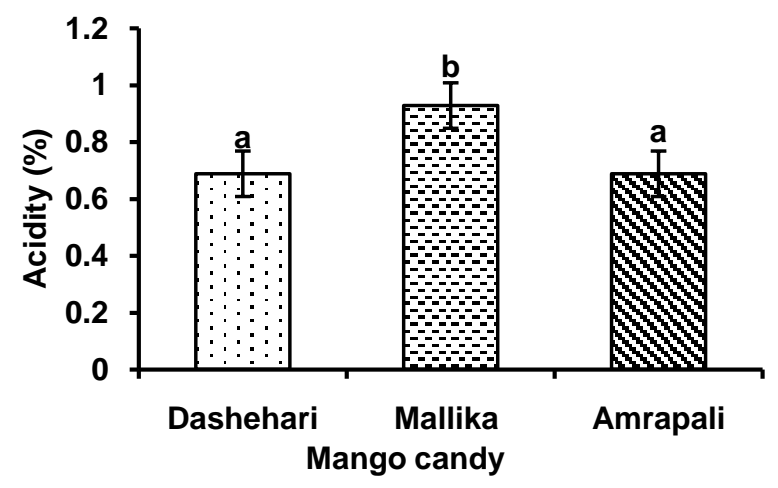

Figure 2. Acidity (\%) of raw mango candy Total Carotene content (mg/100g)

Total carotene was measured in raw mango candy. The highest carotene was observed in candy prepared from Amrapali $(1.56 \mathrm{mg} / 100 \mathrm{~g})$ followed by Mallika candy $(0.914 \mathrm{mg} / 100 \mathrm{~g})$ and lowest carotene content was found in Dashehari candy $(0.672$ mg/100g) (Fig. 3). Higher amount of carotene in Amrapali candy may be inferred as carotene abundance of fresh Amrapali fruits.

\section{Moisture (\%)}

Moisture percentage in raw mango candy ranged between $8.98 \%$ to $10.38 \%$ and was estimated maximum in candy developed from Amrapali followed by Mallika (9.26\%) while minimum moisture was measured in 
Dashehari candy (8.98\%) (Fig. 4). Variation in moisture content in candies of mango varieties may be due to variation in tissue structure and texture of mesocarp.
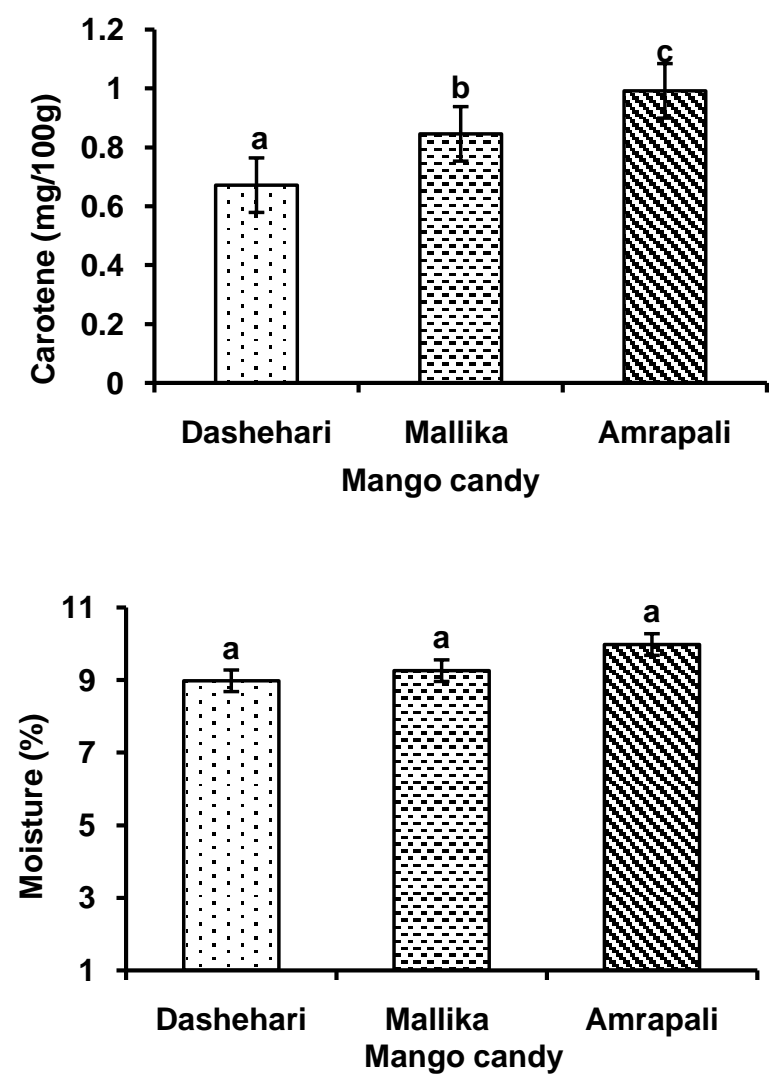

Figure $3 \&$ 4. Total carotene and moisture percent in raw mango candy

\section{Sensory evaluation}

Sensory evaluation is of great importance to both the producer/processor and the consumer. Good quality products attract the consumers by satisfying his aesthetic and gustatory senses. Mango candy was evaluated for taste, texture, flavor and overall acceptability. Dashehari candy was rated highest (7.57) followed by Amrapali (7.43) and Mallika (6.21) with respect to taste. Same trend was observed with regard to flavor (fig. 6). No difference was observed in Dashehari and Amrapali candy for texture score. Amrapali candy scored highest (8.5) followed by Dashehari (8.3) and Mallika got lowest score (7.1) for overall acceptability.

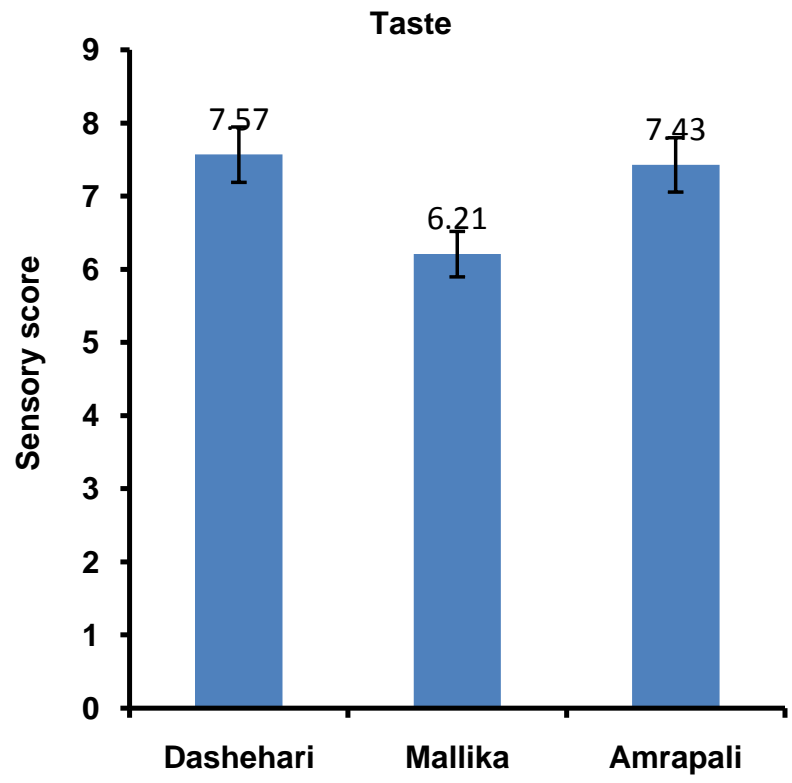

Figure 5. Taste score of mango candy

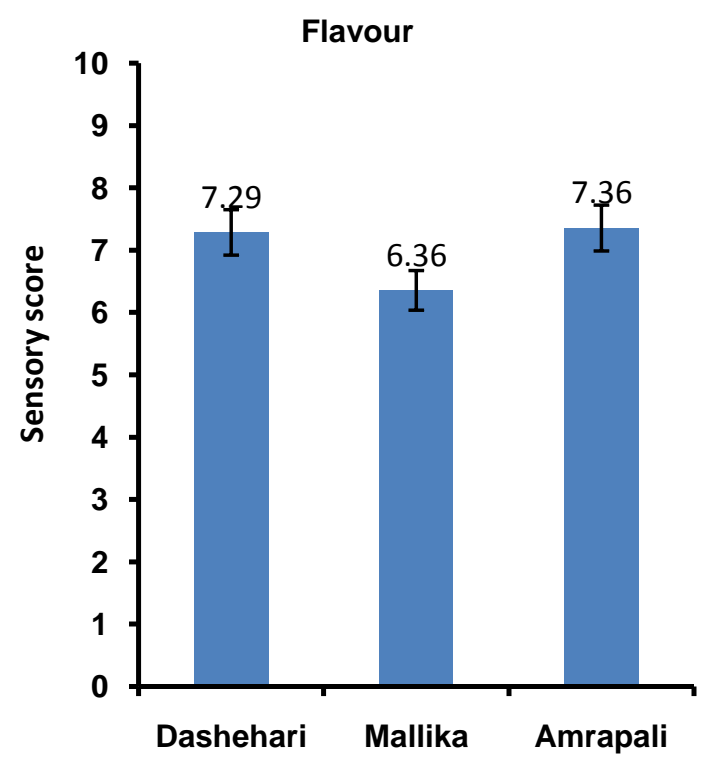

Figure 6. Flavour score of mango candy 


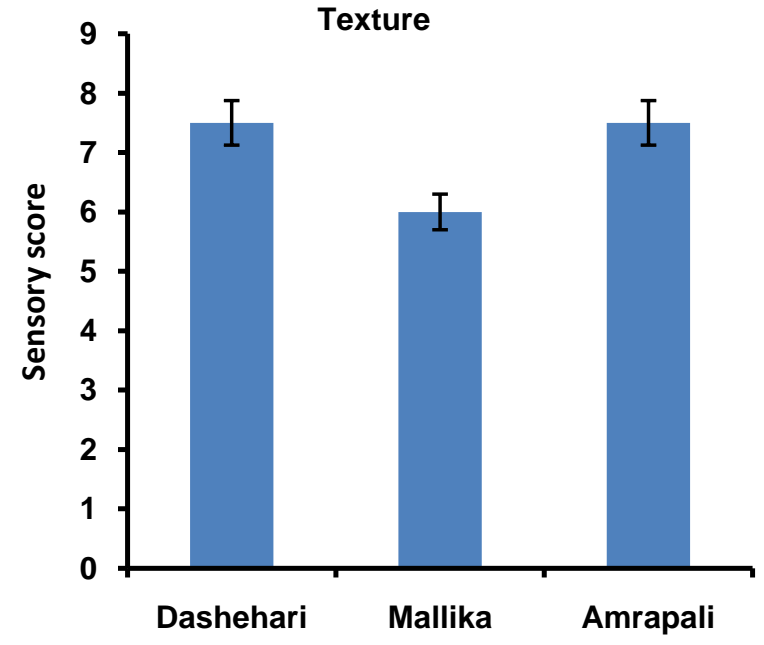

Figure 7. Texture score of mango candy

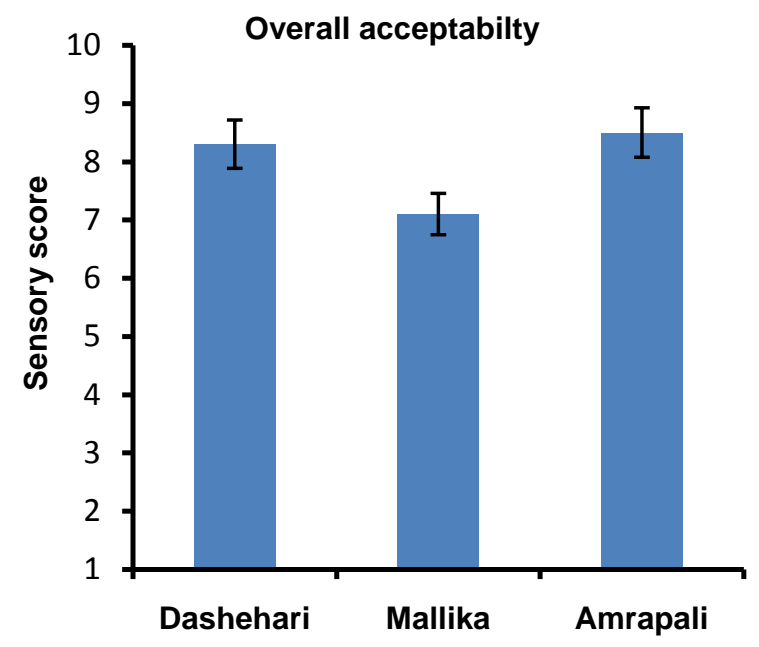

Figure 8. Overall acceptability score of mango candy

\section{Conclusion}

Mango candy is full of energy, vitamins and having good sensory score. It is concluded from the study that raw mango fruits dropped due to strong winds during May-June may be utilized for value addition by mango growers particularly farm-women. This will reduce fruit wastage and generate employment for rural women and diversify mango processed product basket for small scale enterprises.

\section{References}

Amrine MA, Pangbron RM \& Rossler EB. 1965. Principal ofSensory Evaluation of Foods. Academic Press Inc., New York, USA.

Anusuya R, Vijayakumar RM, Srividhya S \& Sivakumar R. 2018. Comparison of physiological and flowering parameters of main and off season by using different plant nutrients and growth hormone in mango (Mangifera indica L.) cv. Bangalora. Journal of Agriculture and Ecology, 5: 76-82.

AOAC. 1984. Official Methods of Analysis, 14thed. Association of Official Analytical Chemists, Washington D.C., USA, 260p.

Kumar K, Gora JS \& Singh CP. 2019. Bioefficacy of paclobutrazol on growth, flowering, fruiting and yield attributes of mango cv. Dashehari under Pantnagar agro-climatic condition. Journal of Agriculture and Ecology, 7: 27-37.

Rangana S. 2010. Analysis and quality control for fruit and vegetableproducts. Tata McGraw Hill Ltd. New Delhi.

Salunkhe DK \& Desai BB. 1984. Postharvest biotechnology of vegetables.Vol.1 CRC press Inc., Florida, USA.

Sheron OP, Tonk DS, Kaushik LS, Hasija RC \& Pan-nu RS. 1998. Statistical Software Package for Agri- cultural Research Workers. Recent Advances in information theory, Statistics and Computer Applications by D.S. Hooda and R.C. Hasija Department of Mathemat- ics Statistics, CCSHAU, Hisar (139-143). 